\title{
Modeling and Simulation Research of Driving Force Generation Speed Control System
}

\author{
Wei WANG ${ }^{1}$, Yu-Heng FAN ${ }^{2, a,{ }^{*}}$, Jian-Feng WANG ${ }^{3}$, Chu-Feng RAO $^{4}$ and \\ Ze-Hao PANG ${ }^{5}$
}

${ }^{1}$ Air Force Engineering University, Air Defense and Antimissile Institute, Xi'an China

${ }^{2}$ Air Force Engineering University, Air Defense and Antimissile Institute, Xi'an China

${ }^{3}$ Air Force Engineering University, Air Defense and Antimissile Institute, Xi'an China

${ }^{4}$ Air Force Engineering University, Air Defense and Antimissile Institute, Xi'an China

${ }^{5}$ Air Force Engineering University, Air Defense and Antimissile Institute, Xi'an China

a614110756@qq.com

${ }^{*}$ Corresponding author

Keywords: Driving Force Generation; Pump Controlled Motor System; Speed Control; Simulink

\begin{abstract}
According to the shortage of the power supply mode of equipment vehicle, a driving force generation speed control is set up to achieve vehicle self-generating when it running. System adopts the high efficiency's hydraulic volume speed-modulating circuit. A constant speed control system which composes of variable displacement pump and fixed displacement motor is researched, and the mathematical model of hydraulic system's each link is established. Using the software of Matlab/Simulink emulates the pump controlled motor system's responding situation, and results show that control system has better speed control ability. The influence of the structure parameters of speed control's performance is investigated and the research also provides the effective reference significant for the achievement of vehicle-based generator system.
\end{abstract}

\section{Introduction}

With the rapid development of modern science and technology, especially in modern warfare, Traditional power-supply modes, such as parked power generation[1], this model requires vehicles to produce electricity in a quiescent state, thus greatly limiting vehicle flexibility. Therefore, it is necessary to realize self-extracting power generation in the process of driving[2-3]. The power of the engine is converted into the constant-speed input of the generator through the power take-off device to realize stable power generation. In recent years, many scholars at home and abroad have done in-depth research on vehicle power generation speed control system, and achieved some research results[4,5], thus promoting the application of driving force generation technology in equipment vehicles.

Through building the modeling analysis of all aspects of the system, using Matlab's Simulink module to simulate the response of the system, and finally the actual experiments are used to verify the model. In addition, the influence of the structural parameters of the speed control system is simulated and analyzed, which provides an effective reference for the control law of the power system and the future improvement of the system.

\section{Establishment and Verification of Hydraulic Speed Regulating System Model}

\subsection{The Composition of Hydraulic Speed Regulating System}

Hydraulic speed control circuit with throttle speed control circuit, volume control circuit and volume throttle circuit $\left.{ }^{[} 6\right]$, and the three speed control methods both have their own advantages and disadvantages. Volume control circuit produces less heat and has high efficiency. In this paper, the hydraulic speed control loop is adopted which uses the variable displacement pump control of the 
fixed displacement motor to realize the constant speed output of the generator under the variable speed disturbance and load disturbance.

The speed control system can control the output of the pump by changing the angle of the pump swashplate by changing the proportional solenoid valve's voltage, and then adjusting the motor speed The speed control system structure as follows:

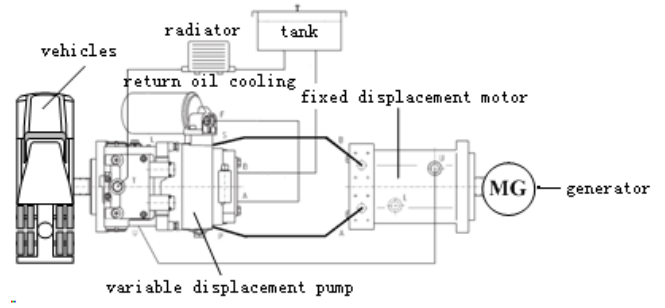

Fig.1 Driving force generation speed control system structure

\subsection{Mathematical Model Establishment of Hydraulic Speed Regulating System}

\section{1) Variable Adjustment Mechanism Composition and Working Principle}

In this paper, the axial piston variable pump is adopted, and its variable adjusting mechanism is integrated in the variable pump. Variables mainly was composed of the electro-hydraulic proportional valve, three four-way valve control hydraulic cylinder, variable swashplate and other parts.

\section{2) Mathematical Model of Current Transfer of Proportional Electromagnet:}

$$
\frac{I(s)}{U_{I}(s)}=\frac{1}{L s+R_{e}}=\frac{\frac{1}{R_{e}}}{\frac{s}{\omega_{T}}+1}
$$

In the formula: $\omega_{T}=\frac{R_{e}}{L}$ is the frequency of the electrical inertia link of the proportional solenoid coil, $R_{e}$ is the internal resistance of the coil

3) The Mathematical Model of the Servo Valve:

$$
\frac{x_{V}(s)}{I(s)}=\frac{K}{\frac{s^{2}}{\omega_{n V}^{2}}+\frac{2 \xi_{V} s}{\omega_{n V}}+1}
$$

In the formula: $x_{V}$ is the spool displacement, $\omega_{n V}=\sqrt{\frac{K_{y}+K_{f}+K_{f V}}{m_{T}+m_{V}}}$ is the servo valve hydraulic natural frequency, $K_{y}$ is the sum of displacement force gain and zero spring stiffness, $K_{f}$ is the spool feedback spring stiffness, $K_{f V}$ is acting on the spool on the steady-state hydraulic dynamic stiffness coefficient, $m_{T}$ is the quality of the armature assembly, $m_{V}$ is the spool quality,

$\xi_{V}=\frac{1}{2} \sqrt{\frac{\left(B_{T}+B_{V}\right)^{2}}{\left(m_{T}+m_{V}\right)\left(K_{y}+K_{f}+K_{f V}\right)}}$ is the servo valve dimensionless damping coefficient, $B_{T}$ is the armature components of the damping coefficient, $B_{V}$ is the spool damping coefficient, $K=\frac{K_{I}}{K_{y}+K_{f}+K_{f V}}$ is the gain coefficient of the servo valve

\section{4) Mathematical Model of Valve-controlled Hydraulic Cylinder}

The variable displacement mechanism of the variable displacement pump is composed of a three-position four-way valve-controlled symmetrical double-acting hydraulic cylinder position servo mechanism. The transfer function of the piston displacement of the valve cylinder is: 


$$
\frac{x_{p}(s)}{x_{V}(s)}=\frac{\frac{k_{q}}{A_{p}}}{s\left(\frac{s^{2}}{\omega_{h}^{2}}+\frac{2 \xi_{h}}{\omega_{h}} s+1\right)}
$$

In the formula: $x_{p}$ is piston displacement, $A_{p}$ is the hydraulic cylinder piston effective area, $\omega_{h}$ is the hydraulic cylinder natural frequency, $\xi_{h}$ is the pump control motor damping coefficient, $k_{q}$ is the proportion of steady-state operating point flow gain

\section{5) Mathematical Model Establishment of Pump-Motor System}

Combined with the study of the speed control system's requirements, the model is simplified. The pump hydraulic motor transfer function is showed as follows :

$\theta(s)=\frac{\frac{k_{q p} n_{p}}{D_{m}}-\frac{C_{t}}{D_{m}^{2}}\left(1+\frac{V_{0}}{\beta_{e} C_{t}} s\right) T_{L}}{s\left(\frac{s^{2}}{\omega_{c}^{2}}+\frac{2 \xi_{c}}{\omega_{c}} s+1\right)}$ (4)In the formula: $k_{q p}$ is variable pump flow gain, $n_{p}$ is the pump input speed, $D_{m}$ is motor displacement, $C_{t}$ is the pump motor total leakage coefficient, $V_{0}$ is the total volume of the pump-controlled motor, $T_{L}$ is the motor output torque, $\omega_{c}$ is the hydraulic natural frequency, $\omega_{c}=\sqrt{\frac{\beta_{e} D_{m}^{2}}{V_{0} J_{t}}}, \xi_{c}$ is the damping ratio, $\xi_{c}=\frac{C_{t}}{2 D_{m}} \sqrt{\frac{\beta_{e} J_{t}}{V_{0}}}+\frac{B_{m}}{2 D_{m}} \sqrt{\frac{V_{0}}{\beta_{e} J_{t}}}, \beta_{e}$ is hydraulic oil elastic modulus, $J_{t}$ is the moment of inertia of the motor

\section{6) Mathematical Model of Speed Sensor}

The dynamic response of the sensor can be seen as a first-order proportional link, the transfer function can be expressed as:

$$
\frac{U(s)}{\dot{\theta}(s)}=k_{f}
$$

According to above all the pump control motor all aspects model, and ultimately the driving force generation speed control system mathematical model is established, the structure is shown in Figure 2.

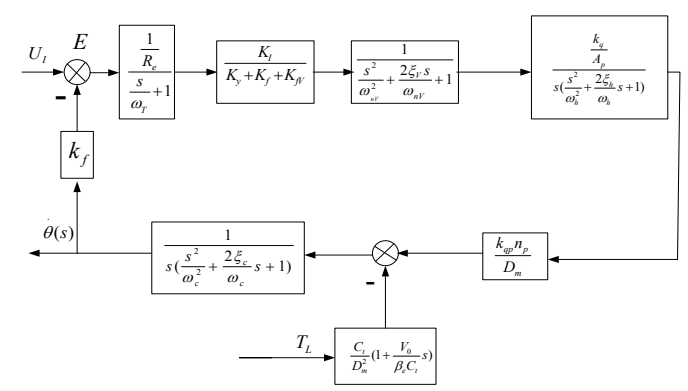

Fig.2 Structure diagram of the mathematical model of the speed-regulating system

\subsection{Control Principle of Hydraulic Speed Regulation System}

Control schematic diagram is shown in Figure 4. The core control strategy of the system is: the control method is based on the combination of PID and feedforward. Feedforward compensation of speed disturbance and voltage signal control of proportional solenoid valve are adopted[7]. In the system, motor output speed as the feedback part and the pump input speed as the feed-forward part.the motor speed ia set at $1500 \mathrm{r} / \mathrm{min}$, the measured motor speed is compared with the set value and the error value is obtained Then by adjusting the proportion of the solenoid valve voltage signal, which changes the displacement of pump to make the motor speed stable at $1500 \mathrm{r} / \mathrm{min}$. 


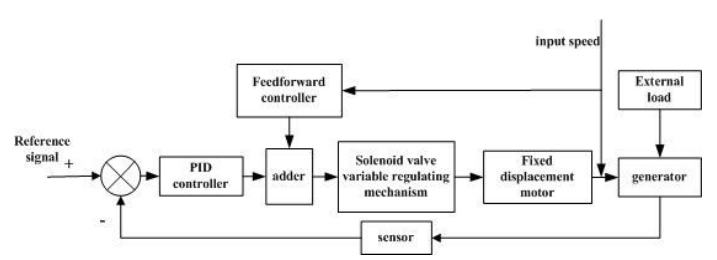

Fig.3 hydraulic speed control system control schematic

\section{Simulation and Verification of System}

According to the mathematic model of the speed control system established in the previous section, the simulink module of Matlab is used to simulate and analyze. The simulation module is shown in Fig.4

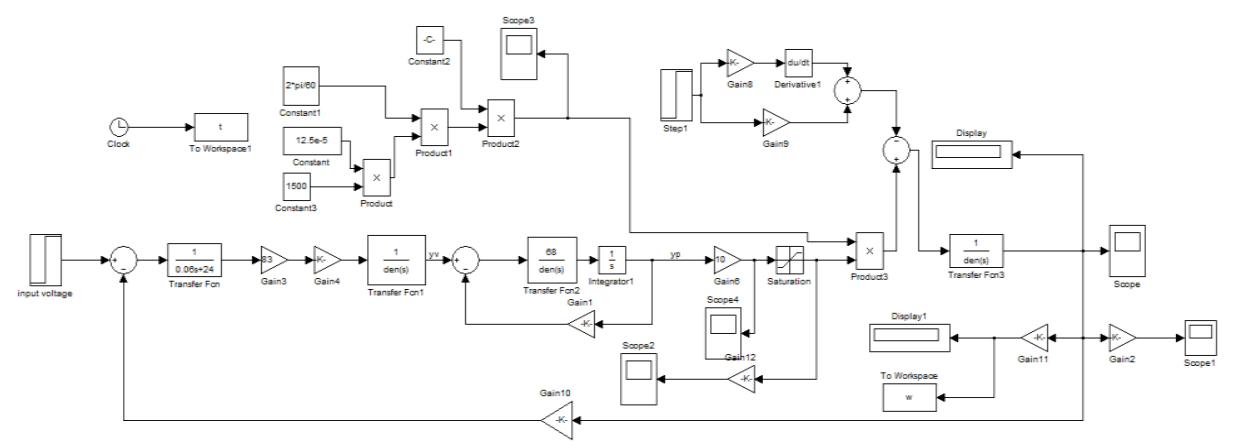

Fig.4 Simulation model of pump control motor speed system

\subsection{Simulation and Verification of Speed and Load Fluctuation}

In order to verify the accuracy of the model, the actual response of the system is verified by setting up a test-bed. Under the conditions of input speed fluctuation and load fluctuation, the control ability of the system is analyzed, and the control law of hydraulic system is obtained. In this paper, the conditions of abrupt change of input speed and external load under different input speed are studied. In figure 5, the speed fluctuation simulation is studied when the input speed is $800 \mathrm{r} / \mathrm{min}, 1500 \mathrm{r} / \mathrm{min}$ and $2500 \mathrm{r} / \mathrm{min}$ separately. Due to the experimental conditions is limited, the experiment was carried out to verify the speed fluctuation at $1500 \mathrm{r} / \mathrm{min}$.

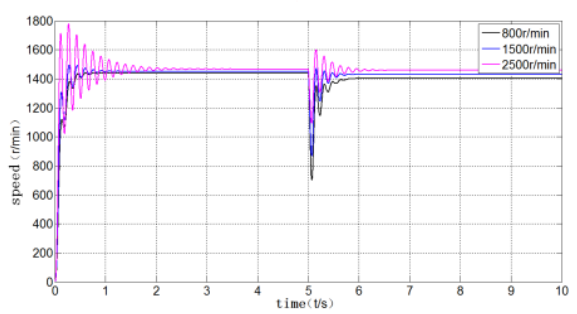

(a) Different input speed and variable speed is $300 \mathrm{r} / \mathrm{min}$

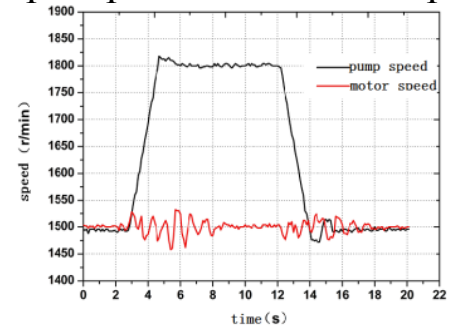

(b) Input speed is $1500 \mathrm{r} / \mathrm{min}$, mutation speed is $300 \mathrm{r} / \mathrm{min}$

Fig.5 Simulation of the speed fluctuation and comparison of the experimental results 
From the results, The motor speed keeps at the $1500 \mathrm{r} / \mathrm{min}$ steadily in the motor speed fluctuation, the range of fluctuations is in $\pm 50 \mathrm{r} / \mathrm{min}$ and the motor speed stability time is less than $3 \mathrm{~s}$, and the change curve is basically the same when the motor is at two different speeds which shows that the system has good tunability to the speed disturbance.

In the figure 6, the speed control system's response to the sudden changes in load conditions is showed.

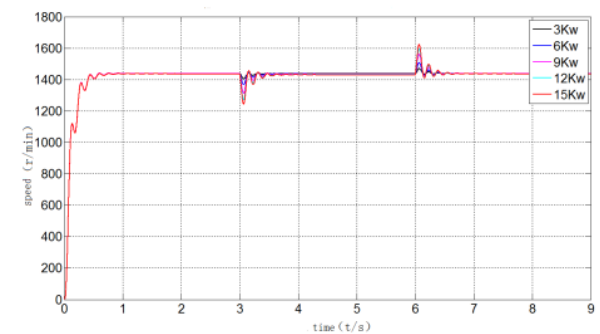

(a)Input speed is $800 \mathrm{r} / \mathrm{min}$ and load is changed

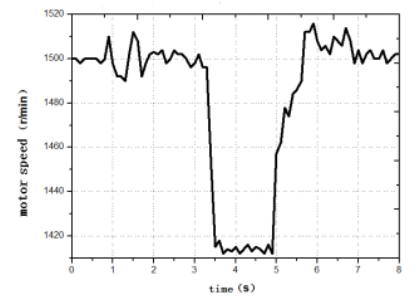

(b)Load mutation $9 \mathrm{Kw}$

Fig. 6 When the input speed is $800 \mathrm{r} / \mathrm{min}$, the simulation of load fluctuation is compared with the experimental results

It can be seen from the figure above when the load changes $9 \mathrm{~kW}$ suddenly, motor speed deviation can reach the maximum $90 \mathrm{r} / \mathrm{min}$, and in the process of loading and unloading, the system speed changes faster, the response time is not more than $300 \mathrm{~ms}$. When load changes suddenly, the motor speed's decrease range is larger than the rising range. Motor speed keeps stable in $2 \mathrm{~s}$, steady-state deviation is about $0.5 \%$, and the maximum instantaneous deviation is $6 \%$. The system reaches the national Class III power generation requirements.

\section{Analysis of Structural Parameters on Stability's Influence of Hydraulic Speed Control System}

As a hydraulic transmission system, the response characteristics of the system must take into account the system's leakage, hydraulic oil elastic modulus, oil viscosity, and motor output load inertia of the system. In this paper, the internal factors of the simulation analysis is took which can provide a reference for the system design and optimization.

\subsection{Influence of Elastic Modulus of Hydraulic Oil on System}

As the hydraulic system in the course of the work, there will be air into, which will affect the elastic modulus of hydraulic oil, In figure 7, when the elastic modulus were 700e6, 1000e6, $1400 \mathrm{e} 6 \mathrm{Mpa}$,speed response curve were showed. 


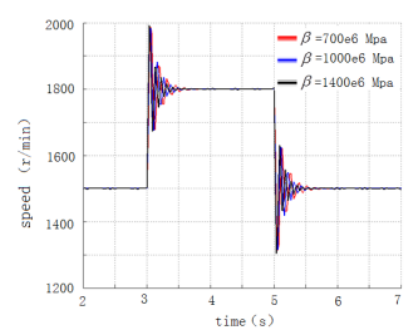

Fig.7 Effect of oil elastic modulus on system response

It can be seen from Fig. 8 that with the increase of the elastic modulus of the hydraulic oil, the response time and overshoot of the system are reduced, and the amplitude of the system shock is also reduced. But the number of shocks remains basically unchanged, indicating that the elastic modulus of oil on the system 's stability is less affected.

\subsection{Influence of Leakage Coefficient of Hydraulic Speed Control System on System Stability}

In figure 8 , the response of the system at three different leakage factors is showed.

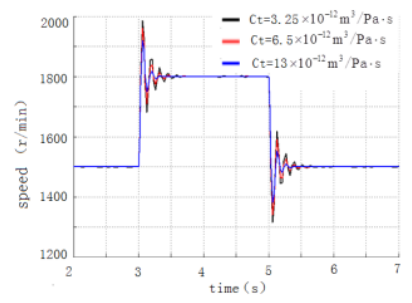

Fig. 8 Effect of leakage coefficient on system response

It can be seen that with the increase of the system leakage coefficient, the overshoot quantity decreases, the system response time and the number of times of oscillation do not change obviously, and the system response condition basically remains unchanged. As the system leakage coefficient is only related to the system damping ratio, the system damping ratio increases when the system leakage increases, so system should increase the leakage coefficient to improve the stability of the system but reduce the system's efficiency. So it is not suitable for the hydraulic speed control system to increase the leakage coefficient to improve the stability of the system.

\subsection{Influence of The Motor Shaft 's Rotational Inertia on The Stability of the System}

In figure 9, the variable pump input speed is $1500 \mathrm{r} / \mathrm{min}$, the hydraulic speed control system response curve is showed when the hydraulic motor moment of inertia were $0.035,0.07,0.15 \mathrm{~kg} \bullet \mathrm{m} 2$.

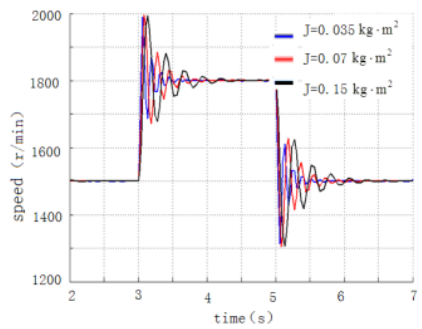

Fig.9 Effect of motor load moment of inertia on system response

From the response curve of Fig.9, the overshoot increases with the increase of the moment of inertia of the motor, and the dynamic adjustment time becomes longer and the system response becomes gentler. It shows that the dynamic response of the hydraulic speed control system under the low load quality is better than the high load quality. 


\section{Conclusion}

In this paper, Simulink module of Matlab is used to simulate and analyze all the links of power generation, and the experimental system is built to validate the model. The results show that the system has good speed characteristics, can effectively reflect the actual working conditions, the power generation system meets the national power generation III requirements finally.

The simulation results show that the input speed of the variable pump has little effect on the response characteristics, and the load fluctuation has a great influence on the response of the hydraulic pump control motor system. So in the hydraulic speed control system, the motor speed should overcome the impact which is caused by load fluctuations furthest, so that the system can have better speed performance. The elastic modulus can be appropriately increased to improve the transient index of the system. At the same time, the system can obtain a better response characteristic through the improved leakage coefficient, but the efficiency will be reduced. And when system is under the low load, the system of the hydraulic speed regulation system's quality response is better than high load. Therefore, the system should be preferred in the design process with higher modulus of the oil, and should maximize the system sealing performance, and choose the low inertia load which has better balance.

\section{References}

[1] WAN Li-rong, Zhao Sheng-gang, Shen Xiao,et al. Dynamic simulation of variable displacement pump variable displacement motor volume speed modulating system based on matlab/ simulink[J].Coal Mine Machinery,2007,28 (2):26-28.

[2] ZHAO Jing-hua, WEN Zhuo-tai. Application of Engine Driven Generator System in Powering Appliance of In-vehicle Equipment [J]Special Purpose Vehicle,2009,(5):63-64.

[3] HANG Fang, LUO Yun-xing. Development of Special Car Load Generating Electricity System Called Halt Car Taking Dint Generating Electricity[J].New Technology \& New Process,2011(1):1-3

[4] GUO Chu-sheng, WANG Xiang-zhou, WANG Yu.LMI approach torobust $\mathrm{H} \infty / \mathrm{H} 2$ controller design with regional poles constraint of a pump-motor system[J].Journal of Beijing Institute of Technology,2006,15(1):57-61.

[5] Andreas Kugi. Modeling and simulation of a hydrostatic transmission with variable-displacement pump[J]. Mathematics and computers insimulation,2000,53(4):409-414.

[6] Wang Zhan-lin. Modern hydraulic control [M].Beijing: China Machine Press,1997.

[7] XIE Zhi-yan, Ma Xun-ming, Li Bo. Research of Wind Power Control System Based on Feedforward and PID Control Technology[J].Microelectronics\&Computer,2014(31):177-179. 